\title{
Considerações sobre a importância da individualidade e das diferenças pessoais de concepção para a formação do educador
}

\section{Considerations on the importance of individuality and personal differences of conception for teacher education}

\author{
Gustavo Pereiraํㅣ | gustavogp@msn.com \\ Celso Sánchez
}

\section{RESUMO}

As discussões concernentes à Educação, em particular no processo de formação do educador, clamam por relevância. No entanto, relativamente pouca atenção tem sido dada a esse aspecto. O presente estudo, em forma de ensaio, procura evidenciar a importância que as diferentes concepções pessoais acerca da Ciência (em caso específico, das Ciências Biológicas) apresentam no processo de formação de professores, apontando brevemente para algumas influências destas individualidades, tanto nas práticas docentes, quanto na elaboração de metodologias para o ensino de Ciências. Pressupomos que todo e qualquer campo científico admite um duplo aspecto em sua concepção: autenticidade e pluralidade. A noção de autenticidade adotada neste texto é entendida pela interpretação de que qualquer concepção de Ciência depende, de certa parte, de uma rede própria de valores e princípios que nos constitui, fazendo com que tal concepção seja sempre individual, intransferível e, portanto, legítima. A ideia de pluralidade aqui trabalhada, por sua vez, pode ser entendida como a noção de que, em linhas gerais, a Ciência admite distintos graus de concepção sobre seu objeto, consoante o ângulo de investigação adotado por quem o concebe, ângulo este resultante de princípios epistemológicos, filosóficos, sociais, éticos, religiosos, etc. Pôde-se concluir que cada indivíduo, mediante sua individualidade, concebe necessariamente a Ciência de maneira toda própria. Assim, no processo de formação do educador, o foco deve se voltar para a problematização consoante à individualidade e às diferenças de concepção de todos os atores envolvidos em tal situação.

Palavras-chave: Diferença; Individualidade; Pluralismo; Formação do Educador.

\footnotetext{
1 Biólogo, graduando em Filosofia pela Universidade do Estado do Rio de Janeiro (UERJ) e mestrando em Educação pela Universidade Federal do Estado do Rio de Janeiro (UNIRIO).

2 - Biólogo e Doutor em Educação pela PUC-Rio. Professor da Escola de Educação e do Programa de Pós-Graduação em Educação da Universidade Federal do Estado do Rio de Janeiro (UNIRIO).
} 


\section{ABSTRACT}

The discussions concerning Education, especially on the process of Teacher Training area, have been clamoring for relevance. However, relatively little attention has been provided to this aspect. This paper, on an essay form, aims to highlight the importance that different personal conceptions about Science (in this specific case, Biological Science) show in the process of Teacher Training, also pointing briefly to some influences of these individualities, both on teaching processes, and on developing methodologies to Science teaching. We assumed that any scientific field admits a dual aspect in its conception: authenticity and plurality. The notion of authenticity adopted in this text is understood by the interpretation that any conception of Science depends, somehow, on an own network of values and principles that constitute us, which makes such conception always individual, non-transferable and, therefore, legitimate. The idea of plurality adopted, in turn, can be understood as the notion that, in general, Science admits several degrees of conception on its object, depending on the angle of investigation adopted by whoever conceives it, which is a result of many principles such as epistemological, philosophical, social, ethical, religious, etc. It was concluded that each individual, through their individuality, necessarily conceives Science on its own way. Thus, in the process of Teacher Training, the focus must turn to the problematic depending on the individuality and the differences of conception of all people involved in such a situation.

Key Words: Difference; Individuality; Pluralism; Teacher Training. 


\section{INTRODUÇÃO}

As discussões concernentes à Educação têm adquirido cada vez mais relevância acadêmica e social, em conformidade com a crescente expansão e solidificação do campo, conforme bem retrata o estudo de Nosella (2010). Em particular no processo de formação do educador, as pesquisas clamam por um olhar mais dedicado sobre os processos fundamentais que aí se estabelecem. No entanto, relativamente pouca atenção tem sido dada a esse aspecto, tanto entre professores, formadores de professores e investigadores da área. (MORTIMER \& SCOTT, 2002).

Para que a reflexão aqui proposta tenha início, é preciso deter-se sobre alguns elementos importantes neste cenário. Começando pela noção de Ciência, se fosse concedida uma grande licença para se reduzir a poucas palavras o que esta significa, espera-se não haver grandes protestos a um enunciado que declare, em linhas gerais, que a Ciência pode ser entendida como uma maneira bastante particular de investigação do mundo, que obedece a regras muito peculiares, de uma dada comunidade: a comunidade científica.

Chizzotti (2006, p.19) defende a ideia de que se pode identificar uma espécie de esforço na construção da realidade e na interpretação que as ciências fazem dessa. Neste sentido, sua posição declara que este esforço não é fruto de uma inteligência isolada em um tempo abstrato, mas é um produto histórico e social porque resulta de um esforço coletivo e permanente da humanidade, no curso do tempo, para construir todas as dimensões da vida. Assim, este tal esforço poderia estar associado justamente à construção de uma concepção pessoal acerca da Ciência.

Da mesma forma como se procede com a investigação científica puramente (mas não meramente) acadêmica ou laboratorial, o trabalho do ensino de uma Ciência no âmbito da formação superior de professores, nas licenciaturas das Universidades, também requer dos estudantes uma espécie de vinculação epistemológica automática ou, mais claramente, uma adoção de perspectiva própria no que concerne ao campo de conhecimento com que se estabelece uma relação de estudo, isto é, em suma, requer uma concepção individual da Ciência.

Em termos práticos, para Aguiar Jr. (1998), é um fato firmemente estabelecido por inúmeras pesquisas que o aluno constrói um sentido pessoal às informações que professor, textos e materiais instrucionais lhes oferecem. Por esse motivo, não é possível desvincular o estudo e o ensino de uma Ciência, processos esses que necessariamente se dão na formação superior de professores (de Biologia, em particular, como exemplo do caso específico que se propôs tomar como emblema para esta discussão), de uma adoção de perspectiva pessoal, mediante a qual o campo científico em questão adquire um tom próprio, uma característica marcada pela individualidade dos atores ali envolvidos.

Neste sentido, o presente estudo, em forma de ensaio, procura discutir a importância que as diferentes concepções pessoais acerca da Ciência (em caso específico, das Ciências Biológicas) apresentam no processo de formação de professores. Num segundo momento, pretende-se simplesmente chamar atenção para algumas influências que estas individualidades podem acarretar, tanto na prática dos processos docentes, quanto na elaboração de metodologias para o ensino.

Ora, a prática educativa de formação do educador é um processo que requer dedicação e tratamento especiais, visto que os educadores formados serão os futuros detentores de certa forma de poder sobre a sociedade, a qual se apoia quase cegamente na função da escola, sem uma devida reflexão sobre a qualidade de formação humana que ali se estabelece. Isto significa dizer que a formação de educadores é uma questão educacional que gera, direta ou indiretamente, diversas implicações sociais, e o ensino de ciências, por sua vez, exige uma constante reavaliação de seus próprios processos e realizações.

Assim, a relevância deste problema esboçado justifica-se na intenção de apontar caminhos que sejam coincidentes com o mérito e com a magnitude reais da reflexão teórica exigida pelo campo da formação de pro- 
fessores, chamando a atenção para que algumas de suas questões que se dão no interior do processo de formação do educador não sejam negligenciadas.

\section{SUPORTE TEÓRICO-METODOLÓGICO}

Pressupomos que todo e qualquer campo científico admite um duplo aspecto em sua concepção: autenticidade e pluralidade.

De um lado, a noção de autenticidade adotada neste texto é entendida pela interpretação de que qualquer concepção de Ciência depende, de certa parte, de uma rede própria de valores e princípios que nos constitui. De acordo com Mortimer \& Scott (2002), muitas dessas pesquisas têm adotado, como perspectiva teórica, aquela relacionada à corrente sócio-histórica ou sociocultural. Nessa tradição, o processo de conceitualização é equacionado com a construção de significados (VYGOTSKY, 1987 apud MORTIMER \& SCOTT, 2002), o que significa que o foco é no processo de significação que, para o autor, se estabelece no ato individual de nomeação e classificação do mundo. Como resultado, uma determinada concepção nunca poderá revelar-se sob a mesma maneira em diferentes indivíduos, sendo esta sempre individual, intransferível e, portanto, legítima.

Assim, essa tendência atual da prática de formação de educadores, inclusive da prática de ensino de Ciências, sinaliza um deslocamento dos estudos sobre o entendimento individual dos estudantes (DUIT and TREAGUST, 1998 apud MORTIMER \& SCOTT, 2002).

Por outro lado, plural é, por definição, aquilo que indica mais que um. Dito de outra maneira, o pluralismo é, então, a qualidade daquilo que não é único, isto é, uma posição que admite mais que uma coisa, ideia ou categoria. Quando se concebe o pluralismo, automaticamente se instala a noção de multiplicidade. Com base em Laburú et al. (2003), dentro desse ponto de vista, este trabalho propõe desenvolver argumentos, indicando uma proposta metodológica pluralista para a educação científica, pois parte do pressuposto de que todo processo de ensino-aprendizagem é altamente complexo, mutável no tempo, envolve múltiplos saberes e está longe de ser trivial.

A Filosofia, por exemplo, traz uma grande contribuição para a concepção de pluralismo que se pretende adotar aqui: esta concepção não admite, no mundo, senão seres múltiplos e individuais. Em outras palavras, o pluralismo baseia-se na existência necessária de grupos ou indivíduos distintos e independentes, exigindo sempre certo grau de diferença entre tais entes.

A ideia de pluralidade aqui trabalhada, por sua vez, pode ser entendida como a noção de que, em linhas gerais, a Ciência admite distintos graus de concepção sobre seu objeto, consoante o ângulo de investigação adotado por quem a concebe, ângulo este resultante de princípios epistemológicos, filosóficos, sociais, éticos, religiosos, etc.

Decorre deste ponto que a noção que permeia todo este panorama, cuja totalidade da complexidade não está sendo posta em discussão é, em termos de processos de formação humana, a de individualidade.

\section{A CONCEPÇÃO INDIVIDUAL E LEGÍTIMA: POR UMA EMERGÊNCIA DO PLURALISMO}

A atividade de uma Ciência é sempre um processo vivo. Com isso, admite-se que o fazer científico recebe influências diretas da vontade do homem, do momento histórico vigente (especialmente no aspecto sociopolítico) e, assim, transforma-se ao longo do tempo. Não há, então, uma espécie de fixidez absoluta dos conhecimentos de uma certa área do saber; todos eles encontram-se sempre no status de desenvolvimento, sob constantes (re)construções.

Essa ideia de que cada sujeito constrói uma concepção individual diferente sobre a Ciência pode ser entendida como fruto de um acontecimento pessoal, ou seja, íntimo, que se dá entre duas dimensões que entram 
em combinação neste sujeito. De um lado, há o conhecimento científico que lhe afeta, “objetivamente”; de outro, existe uma rede própria e intransferível de valores e princípios que lhe constitui. Como resultado desse cotejo entre conhecimento (que se pretende) objetivo e valores e princípios individuais, nasce uma concepção pessoal de uma Ciência, portanto sempre diferente de infinitas outras concepções possíveis. A compreensão de uma Ciência é, então, plural, conforme a pluralidade, a diversidade de indivíduos que participam desta compreensão.

A ideia contida, portanto, é a de que essa perspectiva da pluralidade se mostra potencialmente mais eficaz para se construir uma crítica reflexiva acerca de certa fragilidade de alguns elementos de fundamento, que sustentam os processos de formação de professores (caso particular das licenciaturas em biologia, a partir da qual essa discussão pode ser extrapolada para a formação do educador em geral) e do ensino, na medida em que se procura evidenciar a pertinência e a indispensabilidade de algumas questões que se apresentam no âmbito das diferenças individuais de concepção para estes processos educacionais.

Além disso, procura-se dar o devido crédito à consideração da forma como as experiências e etapas particulares dos indivíduos influenciam o processo de desenvolvimento de suas potencialidades, devido às diferenças individuais que estes exibem.

\section{O PROBLEMA DO ACESSO AO OUTRO}

Frente à defesa explicitada, que remonta ao discurso da individualidade, da pluralidade e da constituição pessoal do sujeito, uma dificuldade parece tomar corpo e ameaçar, a partir dos fundamentos, tal perspectiva pluralista sugerida para os processos de formação de professores e de ensino de ciências, pela máxima da individualidade. Tal dificuldade se revela no problema acerca do outro, do diferente, do apartado do eu. (HERMANN,2011)

Ora, se os processos de formação do educador e de elaboração de metodologias referentes ao ensino de ciências devem admitir a condição das diferenças de concepções individuais, instaura-se assim, automaticamente, uma barreira epistemológica entre os infinitos “eus”, tornando cada um destes “eus” inacessíveis entre os diferentes sujeitos, os "outros", tecendo-se, dessa forma, uma dificuldade de conexão entre sujeitos e conhecimentos. Em outras palavras, torna-se possível identificar uma arena para as individualidades plurais que passariam a se articular numa rede complexa de significados.

Uma solução apontada para tal dificuldade pode ser encontrada na busca pelo acesso ao outro. Parece natural que esta tendência de acesso ao outro surja justamente como a única e a mais bem construída tática de superação das distâncias inauguradas pelas diferenças individuais de concepção.

O outro é justamente aquilo que nos é distinto, o estranho à identidade. Assim, o acesso poderia ser um movimento que permitiria a uma individualidade o estabelecimento dos parâmetros para a configuração de comunicação com outra [individualidade] e, a partir de então, alguma forma efetiva de troca estaria permitida a ser estabelecida, em princípio.

Entretanto, a grande questão basal vinculada nesta tendência de acesso ao outro apenas faz sentido se admitir, por sua vez, uma multiplicidade atrelada aos indivíduos, uma diferença nos sujeitos, ou seja, uma diferença intrínseca a estes. É somente desta maneira que a tentativa de acesso ao outro se ajusta às diferenças de concepção individuais, ao invés de superá-las. Isto significa que a proposta do acesso ao outro está mais próxima de exercer uma afirmação positiva da existência real das diferenças individuais do que de uma refutação desta perspectiva.

Por outro lado, em adição, há uma busca incessante por uma concepção que sugere que pode haver no eu a identidade e o estranho, mas tal reconhecimento ou abertura é obstaculizada por uma estrutura de pensamento que tende à unidade e à finalidade. (HERMANN, 2011, p.139) 


\section{DIFERENÇAS DE CONCEPÇÃO, PRÁTICA DOCENTE E ENSINO DE CIÊNCIAS}

O início deste breve debate não poderia ser outro senão uma reflexão sobre uma interrogação que vai do campo do teórico e do subjetivo ao campo da ação e da prática. A primeira pergunta que se faz é como se relacionam o saber proposicional, que caracteriza qualquer teoria, e o saber fazer que se manifesta na prática, seja ela ética ou docente? (CARVALHO, 2011, p.307)

Uma grande crítica ao fazer educativo tanto da formação de professores, quanto do ensino de ciências reside em que, muitas vezes, a prática educativa simplesmente se dá, sem uma devida e necessária reflexão acerca do que se faz e se pretende fazer com esta e através desta. Levar em conta, tanto nas práticas docentes, quanto na elaboração de metodologias para o ensino de Ciências, algumas influências das individualidades responsáveis pelas diferenças de concepção é, em certo sentido, erguer uma questão acerca da qualidade da formação educativa que ali se estabelece.

Mas a própria noção de qualidade é algo polissêmico e complexo, que muda e se adapta conforme os diferentes lugares, ao longo do tempo, e sempre subsiste de acordo com uma intencionalidade associada. Estas variáveis que interferem nas diferentes concepções que orientam a formação de professores e o ensino de Ciências forjam linhas de atuação educacional as mais variadas. De acordo com Nazareth \& Fernandes (2012, p.64), considerando que elas se relacionam com o contexto político e local de cada época, e que uma corrente não é suprimida com o fortalecimento de outra, elas coexistem na cultura escolar e influenciam de diferentes formas as práticas educativas (...).

Nas palavras de Coelho (2009, p.85), pode-se também perceber esta postura. A autora afirma que com a educação não é diferente: de acordo com a forma como vêem e entendem o mundo, conservadores, liberais e socialistas (re) apresentam concepções de educação cujas características - diversas em sua(s) natureza(s) engendram práticas também diversas.

Essa noção de pluralidade nas práticas educativas, conforme seja a concepção intrínseca de educação que se faz, tem uma implicação real nas atividades pedagógicas e nas práticas docentes. Por exemplo, na própria seleção de conteúdos (formação de currículo, em linhas gerais) e na consequente aplicação destes, é aceite que o saber de referência científica requer ajustes em sua natureza, função, conteúdo e forma, de maneira que possa ser mais propriamente trabalhado pela instituição escolar, nas suas mais distintas inserções sociais locais, adquirindo, então, caráter de conhecimento escolar.

Nesse sentido, um conteúdo de saber que tenha sido definido como saber a ensinar sofre, a partir de então, um conjunto de transformações adaptativas que irão torná-lo apto a ocupar um lugar entre os objetos de ensino. (CHEVALLARD, 1991, p.39, nt 15 apud LEITE, 2007, p.43)

É preciso considerar que esta espécie de transposição didática é mediada, sob um certo aspecto (dentre vários outros aspectos que também orientam tal procedimento), por concepções pessoais acerca da Ciência e acerca da concepção de ensino de ciências.

Desta forma, as individualidades acarretam grandes implicações na concepção geral de Educação, assim como no ensino de Ciências e Biologia, por conseguinte. A ideia de fundo é que, diferentes indivíduos, com diferentes "histórias de vida", portam distintas e impartilháveis individualidades, sendo estas as fontes, em certa medida, das múltiplas concepções acerca da Ciência, de seu objeto e função, sua natureza, etc., acarretando, em consequência disto, compromissos educacionais distintos e, assim, práticas docentes e metodologias de ensino de ciências igualmente diferentes.

Nas palavras de Carvalho (2011, p.310), 
a uma determinada concepção de homem, sociedade, conhecimento, deveria corresponder uma concepção de escola, aluno, avaliação etc. Em síntese, a cada grande "sistema” ou "teoria” sobre o "homem” corresponderia uma determinada "visão de educação”, “deduzida” desse campo conceitual e de seus ideais éticos, políticos ou epistemológicos.

A esta altura, há de se interrogar quanto ao próprio educador, enquanto um indivíduo que também constrói uma concepção pessoal de Ciência, para si e com vistas ao ensino: espera-se ser possível, nessa condição de professor, livrar-se de forma eficiente das influências das diferenças individuais, de forma a proceder à prática docente sob uma concepção pura e objetiva de uma Ciência, em especial da Biologia?

Ainda cabe ser investigado em outro momento se, de alguma forma, é possível considerar que as particularidades das metodologias aplicadas ao ensino de ciências, ou as diferentes formas de linguagem empregadas pelos docentes, ou até mesmo os conhecimentos construídos em sala de aula permitem inferir de forma fiel as concepções individuais do educador. O resultado de uma proposta como essa pode gerar frutos no sentido de permitir a elaboração de precisos ajustes corretivos e adaptativos no processo de ensino-aprendizagem, tanto no nível da própria formação de educadores, como no nível da educação básica.

Em resumo, relacionar a prática docente e o ensino de ciências com a noção das diferenças de concepção é caminhar no sentido do reconhecimento da importância da pluralidade de formas pelas quais um saber teórico-proposicional (saber que) se relaciona com um saber operativo (saber fazer). (Id. Ibid., p.308)

\section{DISCUSSÃO E QUESTÕES CONSEQUENTES DAS DIFERENÇAS DE CONCEPÇÃO}

Além do problema que se pretendeu expor, no qual cada indivíduo, mediante sua identidade, que é singular, constrói uma concepção individual de Ciência, isto é, concepção sempre diferente de outras concepções possíveis, algumas outras questões ainda merecem ser anunciadas, no âmbito dessa reflexão.

Procura-se admitir, como resultado desta breve reflexão, a existência de diversas concepções acerca de uma mesma Ciência ou objeto científico, instaurando-se múltiplas divergências interpretativas. Nesse sentido, uma possível consequência da adoção da perspectiva da individualidade e das diferenças de concepção acerca de uma Ciência, no cenário de formação de professores, é a dificuldade em se obter parâmetros, diretrizes e critérios que possam legitimar e conferir validade formal aos conhecimentos que venham a ser construídos nesse âmbito.

Mais que isso, é preciso também poder atingir uma espécie de padrão de regularidade no ensino de ciências, pois, em princípio, a noção de qualidade permite uma vasta gama de interpretações acerca de um mesmo procedimento, método ou fenômeno, o que pode ser traduzido numa infinidade de explicações e teorias, muitas vezes antagônicas entre si, sobre um mesmo dado da realidade, concreto ou abstrato. Isso ocorre porque a própria concepção do que vem a ser conhecimento fica submetida à ideia fixa e aos processos de legitimação instituídos para as ciências. (LOPES, 2007, p.189)

Este cenário marcado pela pluralidade não impede, contudo, que haja um conjunto de pressuposições que se refere ao que é a realidade, ao conhecimento que se pode ter dessa realidade e às formas particulares para se conhecer essa realidade. (CHIZZOTTI, 2006 p.22)

Surgiu, assim, a epistemologia como produto da ciência criticando-se a si mesma. (JAPIASSU, 1997, p.67 apud LIMA, 2003, p.99) O olhar epistemológico sobre a produção científica consiste em situá-la no foco do questionamento e da crítica não como fim em si mesmo, mas através deste, viabilizar caminhos que possibilitem uma melhor reflexão e compreensão sobre o que se produz, como se produz, porquê e para que se produz. (LIMA, 2003, p.99) 
Dubet (2011) parece ter reconhecido, analogamente, a mesma situação, acima exposta, ao tratar da questão entre cidadania e escola. Em certo momento de seu texto, escreve: é importante compreender que a cidadania não é una, que ela muda segundo as épocas, os países e as tradições e, sobretudo, que ela não é homogênea, pois abrange várias dimensões mais ou menos contraditórias entre si. Entretanto, pode-se dizer que o autor conclui que, assim como aqui exposto acerca das concepções de Ciência, embora tal condição de cidadão exiba um aspecto multifacetado e fluido, ou seja, plural, tal característica não implica uma impossibilidade total de parâmetros que a definam e a orientem. Neste sentido, ele prossegue: É possível distinguir alguns elementos constantes da cidadania. (DUBET, 2011, p.290)

Em consequência dessa diversidade de olhares qualitativos inevitáveis sobre a Ciência, também é importante que se desconfie da pretensão de imparcialidade muitas vezes associada ao fazer científico. É ilusória a pretensão de validade, objetividade e verdade das teorias científicas. (CHIZZOTTI, 2006, p.24)

Seguindo nessa trilha, os estudos pragmáticos contribuem para essa discussão da verdade e validade científicas. De acordo com William James, para o pragmatismo, o único teste de verdade provável é o que trabalha melhor no sentido de conduzir-nos, o que se adapta melhor a cada parte da vida e combina com a coletividade dos reclamos da experiência. (JAMES, 1979, p.30 apud SAVIANI, 2007, p.290)

Até este ponto, procurou-se defender que uma Ciência é sempre contaminada "em essência”, a priori, por um ângulo de investigação que reflete as condições da "história de vida" ou da individualidade, da diferença interna, de quem assim a concebe. Em suma, pode-se dizer que, ao conceber uma ciência, o pesquisador, cientista, crítico ou professor (caso explicitamente de maior interesse, nessa abordagem) adota ou inventa um caminho de explicação da realidade que investiga ou da descoberta que realiza, guiado por um modo de conhecer essa realidade e de explorá-la, porque tem ou urde uma concepção do que é a realidade que investiga. (CHIZZOTTI, 2006, p.24)

Em relação à produção do conhecimento propriamente dito, as posturas que reconhecem a interferência da individualidade como fonte das diferenças de concepção, a partir das quais os conhecimentos são construídos, parecem ter adquirido força e adeptos numa proporção nunca antes vista. Nos meios acadêmicos menos conservadores, assim como em muitas salas de aula, fica clara a discordância da neutralidade advogada pelos positivistas: o conhecimento não é neutro, mas produto dos interesses, valores, crenças de uma comunidade. (DELLA FONTE, 2010, p.39)

Retomando o percurso até aqui feito, espera-se que tenha sido argumentado o seguinte: esta ideia geral de que a concepção de educação, de ciência, de atuação docente e de ensino de ciência construída é algo sensível a contexto, isto é, que flutua conforme as individualidades que nos constituem, é uma ideia que tem se mostrado cada vez mais presente nas discussões de hoje em dia. Assim, não parece haver resistência a uma conclusão que defenda que a partir de distintas concepções de educação, configuram-se distintas práticas educativas, conforme tal concepção.

Mais que isso, qualquer concepção das Ciências Biológicas, em especial, é ímpar e legítima. Ora, esse aspecto ímpar, isto é, sem outro igual, que se origina da impossibilidade de compartilhamento de forma integral e total de uma concepção individual construída sobre uma Ciência, assim também como esse aspecto de legitimidade, são justamente os resultados acarretados pela adoção de uma visão de diferença individual intrínseca. Estendendo-se este argumento, enfim, cada concepção pessoal da Biologia é resultado da diferença individual que nos constitui.

\section{CONSIDERAÇÕES FINAIS}

Espera-se ter sido possível afirmar que a Ciência, em especial a Biologia, em linhas gerais, admite distintas concepções sobre seu objeto, ou até mesmo sobre um certo fenômeno, consoante o ângulo de investigação adotado por quem constrói uma determinada concepção, ângulo este resultante de princípios epistemológicos, filosóficos, sociais, éticos, religiosos, etc. 
Como resultado, uma determinada concepção pessoal de certa Ciência nunca poderá revelar-se sob a mesma maneira em diferentes indivíduos, sendo esta sempre individual, intransferível e, portanto, legítima.

Em outras palavras, isto equivale a dizer que não há uma mesma Ciência Biológica para todos, mas Biologias ímpares, individuais, autênticas e plurais.

Numa visão holística, a mudança de perspectiva geral e o aumento da qualidade da educação brasileira pretendidas têm de levar em conta distintos fatores que se situam em níveis teóricos e práticos, por vezes absolutamente discrepantes entre si. Consequentemente, uma reformulação significativa da educação é inconcebível sem a correspondente transformação do quadro social no qual as práticas educacionais da sociedade devem realizar as suas vitais e historicamente importantes funções de mudança. (MÉSZÁROS, 2005, p.108)

Assim, no processo de formação do educador, bem como no processo de ensino de ciências, o foco deve se voltar para a assimilação consoante à individualidade e às diferenças de concepção apresentadas por todos os atores envolvidos em tal situação.

Um estudo que investigue as múltiplas diferenças de concepções acerca das Ciências Biológicas diz respeito não apenas ao plano teórico-metodológico da Educação, mas também ao aspecto pragmático, que toca no processo de formação de educadores, assim como no de ensino de ciências, contribuindo para a noção de que em todos os espaços educativos diversos conhecimentos são autenticamente construídos.

Em suma, como Villani e Ferreira (1997: 127) apud Aguiar Jr. (1998) argumentam, pode-se dizer que construir uma concepção individual de Ciência é situar-se em meio a um encontro de subjetividades que entram em ressonância afetiva e cognitiva mirando uma meta, possível ou utópica. 


\section{REFERÊNCIAS BIBLIOGRÁFICAS}

AGUIAR Jr., O. O papel do construtivismo na pesquisa em ensino de ciências. Investigações em Ensino de Ciências, V3(2), pp. 107-120, 1998.

CARVALHO, José Sérgio F. de. “A teoria na prática é outra? Considerações sobre as relações entre teoria e prática em discursos educacionais”. In: Revista Brasileira de Educação. v. 16, n. 47, maio-ago. 2011.

CHIZZOTTI, Antonio. Pesquisa Qualitativa em Ciências Humanas e Sociais. Petrópolis, Rio de Janeiro: Vozes, 2006, pp. 19-32.

COELHO, Lígia Martha C. Costa. História (s) da educação integral. Em Aberto, Brasília, v.22, n 80, p.83-96, abr.2009.

DELLA FONTE, Sandra Soares. “Agenda pós-moderna e neopositivismo: antípodas solidários”. In: Educação \& Sociedade, Campinas, v. 31, n. 110, jan.-mar. 2010.

DUBET, Fraçois. “Mutações cruzadas: a cidadania e a escola”. In: Revista Brasileira de Educação. v.16, n.47, maio-ago, 2011.

DUIT, R. and TREAGUST, D. Learning science: from behaviourism towards social constructivism and beyond. In: B. J. Fraser and K. G. Tobin (Eds.), International Handbook of Science Education, pp. 3-25. Dordrecht: Kluwer Academic Publishers, 1998.

HERMANN, N. Breve investigação genealógica sobre o outro. Educação \& Sociedade, vol.32, n.114, pp. 137-149, 2011.

LABURÚ et al. Pluralismo metodológico no ensino de Ciências. Ciência \& Educação, v.9, n.2, p. 247-260, 2003.

LEITE, Miriam Soares. Recontextualização e transposição didática: introdução à leitura de Basil Berstein e Yves Chevallard. Araraquara, São Paulo: Junqueira \& Marin, 2007.

LIMA, Paulo Gomes. Ciência, Epistemologia e Pesquisa Educacional: a Perspectiva Necessária. In: Tendências Paradigmáticas na Pesquisa Educacional. Artur Nogueira. SP: Amil, 2003, pp. 85-126.

LOPES, Alice Casimiro. “Conhecimento Escolar e Conhecimento Científico: Diferentes Finalidades, Diferentes Configurações”. In: Currículo e Epistemologia. Ijuí, RS: Ed. Unijuí, 2007, pp. 187-204.

MÉSZÁROS, István. A educação para além do capital. São Paulo: Boitempo, 2005.

MORTIMER, E. F. \& SCOTT, P. H. Atividade discursiva nas salas de aula de ciências: uma ferramenta sociocultural para analisar e planejar o ensino. Investigações em Ensino de Ciências, V7(3), pp. 283-306, 2002.

NAZARETH, Henrique Dias Gomes; FERNANDES, Cláudia Oliveira. A retórica por uma educação de qualidade e a avaliação de larga escala. Impulso (Piracicaba), v. 21, p. 63-71, 2011.

NOSELLA, Paolo. A pesquisa em educação: um balanço da produção dos programas de pós-graduação. Revista Brasileira de Educação. Rio de Janeiro, v. 15, n. 43. Abril de 2010.

SAVIANI, Dermeval. História das idéias pedagógicas no Brasil. Campinas, SP: Autores Associados, 2007.

VILLANI, A. e FERREIRA, M. P. As dificuldades de uma professora inovadora. Caderno Catarinense de Ensino de Física, v. 14, n.2: 115-145, 1997.

VYGOTSKY, L. S. Thinking and Speech. In The Collected Works of L. S. Vygotsky; Rieber, R. W.; Carton, A. S. (Eds.). Trans. by Minich, N. New York: Plenum Press. pp 39-285, 1987. 